\title{
High-dose PMA with RANKL and MCSF induces THP-1 cell differentiation into human functional osteoclasts in vitro
}

\author{
ZHUO HAO $\mathrm{LI}^{1-3^{*}}, \mathrm{YU} \mathrm{SI}^{1-3^{*}}, \mathrm{GUO}^{1} \mathrm{XU}^{1}, \mathrm{XI}$ MING CHEN ${ }^{1}, \mathrm{HAO}$ XIONG${ }^{1}$, \\ $\mathrm{LAN} \mathrm{LAI}^{1,3}$, YI QING ZHENG ${ }^{1,2}$ and ZHI GANG ZHANG ${ }^{1-3}$ \\ ${ }^{1}$ Department of Otolaryngology Head and Neck Surgery; ${ }^{2}$ Institute of Hearing and Speech-Language Science; \\ ${ }^{3}$ Guangdong Provincial Key Laboratory of Malignant Tumor Epigenetics and Gene Regulation, Sun Yat-sen Memorial Hospital, \\ Sun Yat-sen University, Guangzhou, Guangdong 510120, P.R. China
}

Received March 30, 2016; Accepted March 7, 2017

DOI: $10.3892 / \mathrm{mmr} .2017 .7625$

\begin{abstract}
Osteoclasts are large multinuclear cells, which serve role in erosive bone disease. However, it is not possible to separate osteoclasts from cortical bone in order to culture the cells for further experiments. Therefore, a human osteoclast model is required to investigate the underlying mechanism of bone destruction. The most commonly-used osteoclast model is the RAW264.7 cell line, a murine mononuclear macrophage cell line; however, there exists no reliable osteoclast model using a human cell line. The aim of the present study was to establish a functional osteoclast model using the THP-1 cell line. Suspended THP-1 cells were stimulated for 2 days with 5 or $100 \mathrm{ng} / \mathrm{ml}$ phorbol-12 myristate-13 acetate (PMA) in order to induce the cells to differentiate into adherent macrophages. A 10-day stimulation with $50 \mathrm{ng} / \mathrm{ml}$ receptor activator of nuclear factor $\kappa-\mathrm{B}$ ligand (RANKL) and macrophage colony-stimulating factor (MCSF) was performed in order to induce macrophage differentiation into osteoclasts. Treatment with high-dose PMA with RANKL and MCSF enabled the THP-1 cells to form tartrate-resistant acid phosphatase-positive osteoclasts, which were able absorb bone in a bone resorption test. Treatment with low-dose PMA with RANKL and MCSF failed to induce THP-1 cell differentiation into osteoclasts. PMA alone, or a combination of RANKL and MCSF alone, is insufficient to stimulate THP-1 cell differentiation into osteoclasts. In the present study, a reliable human osteoclast model was established using the THP-1 cell line. This osteoclast model may provide a useful tool for further studies.
\end{abstract}

Correspondence to: Dr Zhi Gang Zhang, Department of Otolaryngology Head and Neck Surgery, Sun Yat-sen Memorial Hospital, Sun Yat-sen University, 107 Yanjiang West Road, Guangzhou, Guangdong 510120, P.R. China

E-mail: zhangzz0369@126.com

*Contributed equally

Key words: osteoclast, THP-1, phorbol-12 myristate-13 acetate, macrophage colony stimulating factor, receptor activator of nuclear factor $\kappa$-B ligand

\section{Introduction}

Osteoclasts are large multinuclear cells, formed by fusion of macrophages derived from hematopoietic stem cells (1). Osteoclasts are involved in bone remodeling under normal conditions; osteoblasts build the bone matrix, while osteoclasts absorb the matrix. Dysfunction of osteoblasts or over-activity of osteoclasts leads to a breakdown in the balance of bone remodeling. In inflammation (2), osteoclasts are overactive and upregulated, which leads to an imbalance between bone formation and resorption, causing bone loss (3). Diseases associated with osteoclasts frequently arise in the fields of orthopedics (4), stomatology (5), otorhinolaryngology (5) and rheumatology (6).

In order to investigate diseases associated with osteoclasts, it is necessary to culture osteoclasts in vitro. Osteoclasts are terminally-differentiated cells which lack the ability to proliferate; in addition, it is difficult to separate osteoclasts from the surface of cortical bone in vitro. Therefore, it is not possible to separate osteoclasts from cortical bone to culture for further experiments. At present, there are three kinds of cells commonly used for osteoclast modeling: Murine bone marrow cells (BMCs) (7,8); murine RAW 264.7 cells (9); and, human peripheral blood mononuclear cells (PBMCs) (10). Various stimulators have been used, including receptor activator of nuclear factor $\kappa-B$ ligand (RANKL), macrophage colony-stimulating factor (MCSF), tumor necrosis factor- $\alpha$, 1 $\alpha, 25$-dihydroxyvitamin D3, lipopolysaccharide and mercaptopurine (11); only RANKL and MCSF have been identified to be effective.

RAW 264.7 murine monocyte-macrophage cells differentiate into osteoclasts following stimulation with RANKL and MCSF (9); this model is the most commonly used to date.

A combination of tartrate-resistant acid phosphatase (TRAP) staining and a bone resorption test are required to identify osteoclasts, as other osteoclast-like cells may be TRAP-positive (11).

There are few studies using a functional osteoclast model induced from a human cell line (7-10). THP-1 cells are a monocyte cell line derived from a patient with acute leukemia. It remains unknown whether THP-1 cells are able to differentiate into osteoclasts following stimulation with RANKL 
and MCSF. Suspended THP-1 monocytes will differentiate into adherent macrophages with the stimulation of phorbol-12 myristate-13 acetate (PMA), an activator of the protein kinase $\mathrm{C}$ (PKC) signaling pathway (12); macrophages are the intermediate stage between monocytes and osteoclasts.

In order to investigate human osteoclasts, a human osteoclast model is required. The present study aimed to construct a human osteoclast model from THP-1 cells, using stimulation with PMA, RANKL and MCSF.

\section{Materials and methods}

Materials. THP-1 cells were obtained from Zhongshan School of Medicine, Sun Yat-sen University (Guangzhou, China). PMA, RANKL and MCSF were purchased from PeproTech (Rocky Hill, NJ, USA). RPMI 1640 medium, fetal bovine serum (FBS) and penicillin/streptomycin were purchased from Gibco (Thermo Fisher Scientific, Inc., Waltham, MA, USA). TRAP staining was performed using a leukocyte acid phosphatase kit from Sigma-Aldrich (Merck KGaA, Darmstadt, Germany). APC-conjugated anti-cluster of differentiation (CD)14 antibody (CD14-APC; 9017-0149; 1:40) and PE-conjugated anti-CD11b antibody (CD11b-PE; 9012-0118; 1:40) were purchased from eBioscience, Inc. (Thermo Fisher Scientific, Inc.). Sclerites were purchased from Southwest Hospital, Third Military Medical University (Chongqing, China).

Cell adherence. THP-1 cells ( $1 \times 10^{6}$ cells/well) were cultured in RPMI 1640 with $10 \%$ FBS, $100 \mathrm{IU} / \mathrm{ml}$ penicillin and $100 \mu \mathrm{g} / \mathrm{ml}$ streptomycin in 6-well plates in 5\% carbon dioxide at $37^{\circ} \mathrm{C}$. TheTHP-1 cells were incubated with $100 \mathrm{ng} / \mathrm{ml}$ PMA for $0,1,2$ and 3 days respectively, and unattached cells in the supernatant were counted. The cell adherence rate was calculated according to the cell number of THP-1 cells without stimulation.

Flow cytometry. The THP-1 cells were incubated with $100 \mathrm{ng} / \mathrm{ml}$ PMA for 0, 1, 2 and 3 days respectively. The cells were incubated with APC conjugated anti-CD14 (CD14APC) (13) antibody as well as PE conjugated anti-CD11b (CD11b-PE) (14) antibody for $30 \mathrm{~min}$ at room temperature. Following washing with PBS, cells were acquired and analyzed on a BD Jazz flow cytometer (BD Biosciences, San Diego, CA, USA). The obtained data were analyzed using FlowJo software version 7.6.1 (Tree Star, Inc., Ashland, OR, USA).

Osteoclast formation. THP-1 cells $\left(1 \times 10^{5}\right.$ cells/well) were cultured in RPMI 1640 with 10\% FBS, $100 \mathrm{IU} / \mathrm{ml}$ penicillin and $100 \mu \mathrm{g} / \mathrm{ml}$ streptomycin in 48 -well plates in 3 groups, as follows: In $1.5 \mathrm{ng} / \mathrm{ml}$ group (low-dose, group 1a) or $100 \mathrm{ng} / \mathrm{ml}$ (high-dose, group 1b) PMA (12) was added to the medium and the supernatant was removed $48 \mathrm{~h}$ afterwards. Subsequently, $50 \mathrm{ng} / \mathrm{ml}$ RANKL and MCSF (PeproTech) (8) were added to the medium following observation of cellular morphology (whether the suspending cells were adherent and fused to be multinuclear cells) under a Zeiss Axioplan 2 (Zeiss AG, Oberkochen, Germany) light microscope (magnification, $\mathrm{x} 200$ ). The culture medium was replaced with fresh medium and cellular morphology was observed every 2 days for a total
14 days (15). In group 2, $100 \mathrm{ng} / \mathrm{ml}$ PMA was added to the culture medium for 14 days. The medium was replaced and cellular morphology was observed every 2 days. In group 3, $50 \mathrm{ng} / \mathrm{ml}$ RANKL and MCSF were added to the culture medium for 14 days. The medium was replaced and cellular morphology was observed every 2 days.

TRAP staining. Beginning on day 10, TRAP staining was performed on the cells in each group according to the manufacturer's protocol every 2 days, until the appearance of TRAP-positive cells was noted. The cells were fixed in $4 \%$ paraformaldehyde for $30 \mathrm{sec}$ at room temperature and washed 3 times in PBS. The mixture of reagents from the TRAP staining kit was added to each plate in a $37^{\circ} \mathrm{C}$ aqueous bath for $45 \mathrm{~min}$.

Bone resorption test. Sclerites were soaked in $75 \%$ ethanol overnight, and sterilized in a benchtop autoclave for $30 \mathrm{~min}$ before use. Sterilized tweezers were used to place the sclerites into 48-well plates, to which $1 \times 10^{5}$ THP1 cells were added; other treatment steps were the same as for group 1.

Following the appearance of TRAP-positive cells, the sclerites were removed from the 48 -well plates, and washed 3 times with PBS and ultrasound. Following gradient elution using 75, 85 and 95\% ethanol, the sclerites were stained with $0.5 \%$ toluidine blue for $2 \mathrm{~min}$ at room temperature and washed 3 times in PBS (16) to observe resorption lacunae under the Zeiss Axioplan 2 (Zeiss AG) light microscope (magnification, $\mathrm{x} 100$ ).

\section{Results}

THP-1 cells differentiate into macrophages following stimulation with PMA. Suspended THP-1 cells without stimulation exhibited an adherence rate of $0 \%$. The adherence rates of THP-1 cells following stimulation with $100 \mathrm{ng} / \mathrm{ml}$ PMA for 1 , 2 and 3 days were 70.1,94.3 and $97.1 \%$ respectively. Therefore, $>90 \%$ cells were adherent following 2 days of stimulation with 100 ng/ml PMA (Fig. 1A).

Flow cytometric analysis demonstrated that the majority of the THP-1 cells were $\mathrm{CD} 14^{+} / \mathrm{CD} 11 \mathrm{~b}^{-}$prior to stimulation. Following 1 day of stimulation with $100 \mathrm{ng} / \mathrm{ml} \mathrm{PMA,} \mathrm{the}$ percentage of $\mathrm{CD} 4^{+} / \mathrm{CD}_{11 \mathrm{~b}}$ cells was upregulated; however, one-half of the cells were $\mathrm{CD} 14^{+} / \mathrm{CD} 11 \mathrm{~b}^{+}$following 2 days of stimulation and the majority were $\mathrm{CD} 14^{+} / \mathrm{CD}_{11 b^{+}}$following 3 days of stimulation. The results of the present study suggest that 2 days of stimulation with $100 \mathrm{ng} / \mathrm{ml} \mathrm{PMA} \mathrm{is} \mathrm{sufficient}$ to induce THP-1 cell differentiation into CD11b ${ }^{+}$(14) macrophages (Fig. 1B).

High-dose PMA plus RANKL and MCSF induce THP-1 differentiation into human functional osteoclasts

Cellular morphology. In the absence of stimulation, the THP-1 cells were small round cells, suspended in the medium or deposited on the bottom of the plates (Fig. 1C). Following 48 h stimulation with PMA, THP-1 cells differentiated into macrophages; certain cells were adherent with long spindles, while others were large round cells. Cellular morphology was unaltered in the high-dose PMA group compared with the low-dose PMA group (Fig. 2A). Following stimulation with 
A

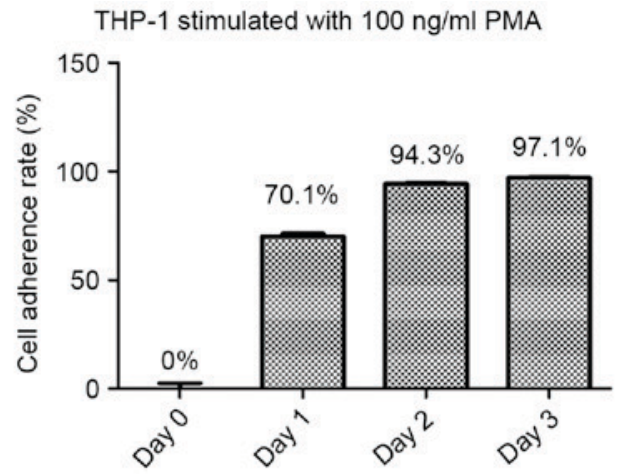

B
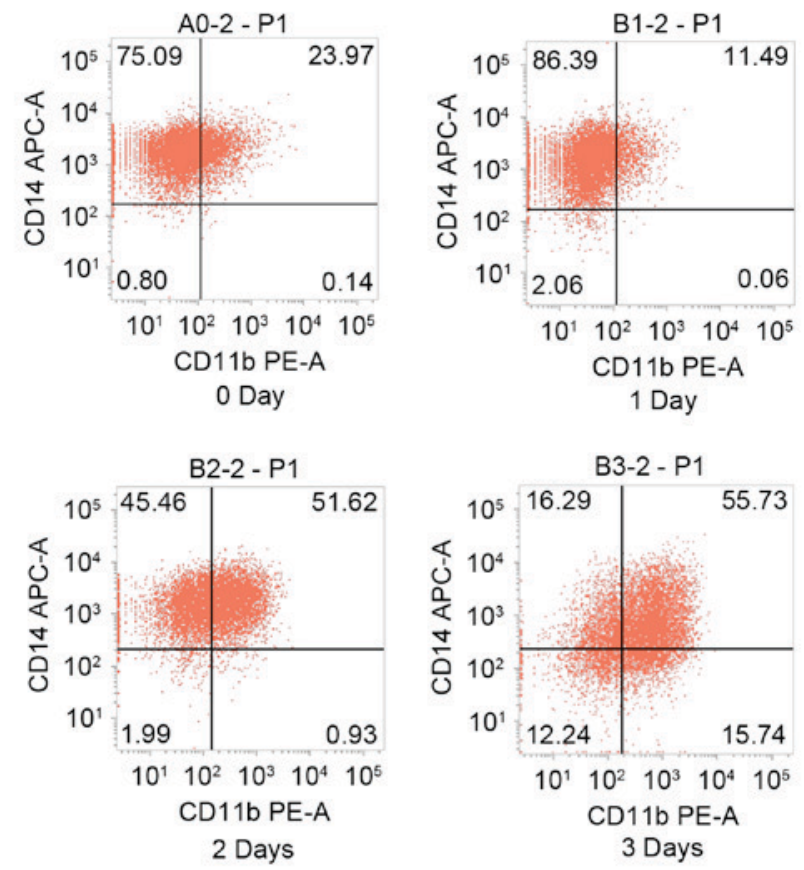

C

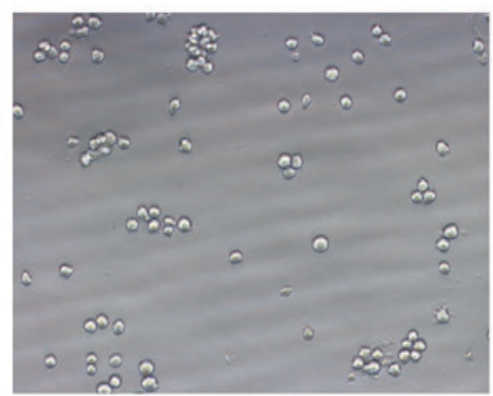

Figure 1. THP-1 cells differentiate into macrophages under stimulation with PMA. (A) The cell adherence rates of THP-1 cells following stimulation with $100 \mathrm{ng} / \mathrm{ml}$ PMA for $0,1,2$ and 3 days were $0,70.1,94.3$ and $97.1 \%$ respectively. (B) Without stimulation, $75.09 \%$ of the THP-1 cells were identified to be $\mathrm{CD} 14^{+} \mathrm{CD} 11 \mathrm{~b}$. Following stimulation with $100 \mathrm{ng} / \mathrm{ml}$ PMA for 1 day, $86.39 \%$ of the THP- 1 cells were identified to be $\mathrm{CD} 14^{+} \mathrm{CD} 11 \mathrm{~b}$; following 2 days of stimulation, $45.46 \%$ of the cells were identified to be $\mathrm{CD} 14^{+} \mathrm{CD} 1 \mathrm{lb}$ and $51.62 \%$ were identified to be $\mathrm{CD} 14^{+} \mathrm{CD} 11 \mathrm{~b}^{+}$; and following 3 days of stimulation, $55.73 \%$ cells were identified to be $\mathrm{CD} 14^{+} \mathrm{CD} 11 \mathrm{~b}^{+}$. (C) The cellular morphology (magnification, x200) of THP-1 cells in the absence of stimulation. CD, cluster of differentiation; PMA, phorbol-12 myristate-13 acetate; APC, allophycocyanin; PE, phycoerythrin.

RANKL and MCSF, the cells were fused further into large multinuclear cells, which were irregular in shape. However, it is difficult to identify osteoclasts solely by cellular morphology
(Fig. 2A). Under stimulation with PMA alone, the THP-1 cells became adherent; however, they did not exhibit further fusion. Under stimulation with RANKL and MSCF only, there was no clear alteration observed in the THP-1 cells; the majority of the cells were suspended or deposited on the bottom of the plates.

Bone resorption test. A total of 2 days of low-dose PMA stimulation followed by RANKL and MCSF did not lead to clear bone resorption. However, high-dose PMA followed by RANKL and MCSF led to clear lacuna formation (Fig. 2B).

Trap staining. In group 1, following 2 days of stimulation with high-dose or low-dose PMA, and 8 days stimulation with $50 \mathrm{ng} / \mathrm{ml}$ RANKL and MCSF, no TRAP-positive cells were identified. Following 2 days of stimulation with high-dose PMA, and 10 days stimulation with $50 \mathrm{ng} / \mathrm{ml}$ RANKL and MCSF, the cells appeared to contain wine-red particles (TRAP-positive) and were multinuclear. However, wine-red particles were not apparent in the low-dose PMA group (group 1a). At day 14, the cells under stimulation with high-dose PMA, RANKL and MCSF appeared to be TRAP-positive and multinuclear. Under 14 days of stimulation with $100 \mathrm{ng} / \mathrm{ml}$ PMA alone, the THP-1 cells differentiated into large TRAP-negative macrophages. However, under 14 days of stimulation with $50 \mathrm{ng} / \mathrm{ml}$ RANKL and MCSF, the THP-1 cells remained as small round cells (Fig. 3).

\section{Discussion}

In the present study, a two-step stimulation process was used in order to construct a human osteoclast model. PMA was used to stimulate THP1 cell differentiation into macrophages, followed by MCSF and RANKL to stimulate macrophage differentiation into osteoclasts. This osteoclast model mimics the recruitment of monocytes from peripheral blood during inflammation and their differentiation into osteoclasts, leading to bone resorption.

THP1 cells are globular suspended monocytes. Under the stimulation of PMA, THP1 cells will differentiate into adherent macrophages with a round or fusiform morphology. Macrophages are large compared with monocytes. According to Park et al (12), there is no difference between using high-dose or low-dose PMA to stimulate THP1 cell differentiation into macrophages, although low-dose treatment may affect cytokine expression. The present study used $50 \mathrm{ng} / \mathrm{ml}$ (8) MCSF and RANKL to stimulate macrophages. MCSF is able to upregulate the expression of RANK, and RANKL facilitates the formation of TRAP-positive osteoclasts (17). In the present study, high-dose PMA was demonstrated to be the principal factor influencing the formation of osteoclasts. Following 12 days of stimulation, the high-dose PMA group exhibited the formation of TRAP-positive osteoclasts which demonstrated positive results in the bone resorption assay.

In the control group, using PMA alone or MCSF with RANKL alone, the formation of osteoclasts was not observed. Consequently, it is necessary to use a two-step method in order to construct osteoclasts. Due to the suspension characteristics of THP-1 cells, PMA is required to promote cellular adherence to the bottom of the culture plate. 


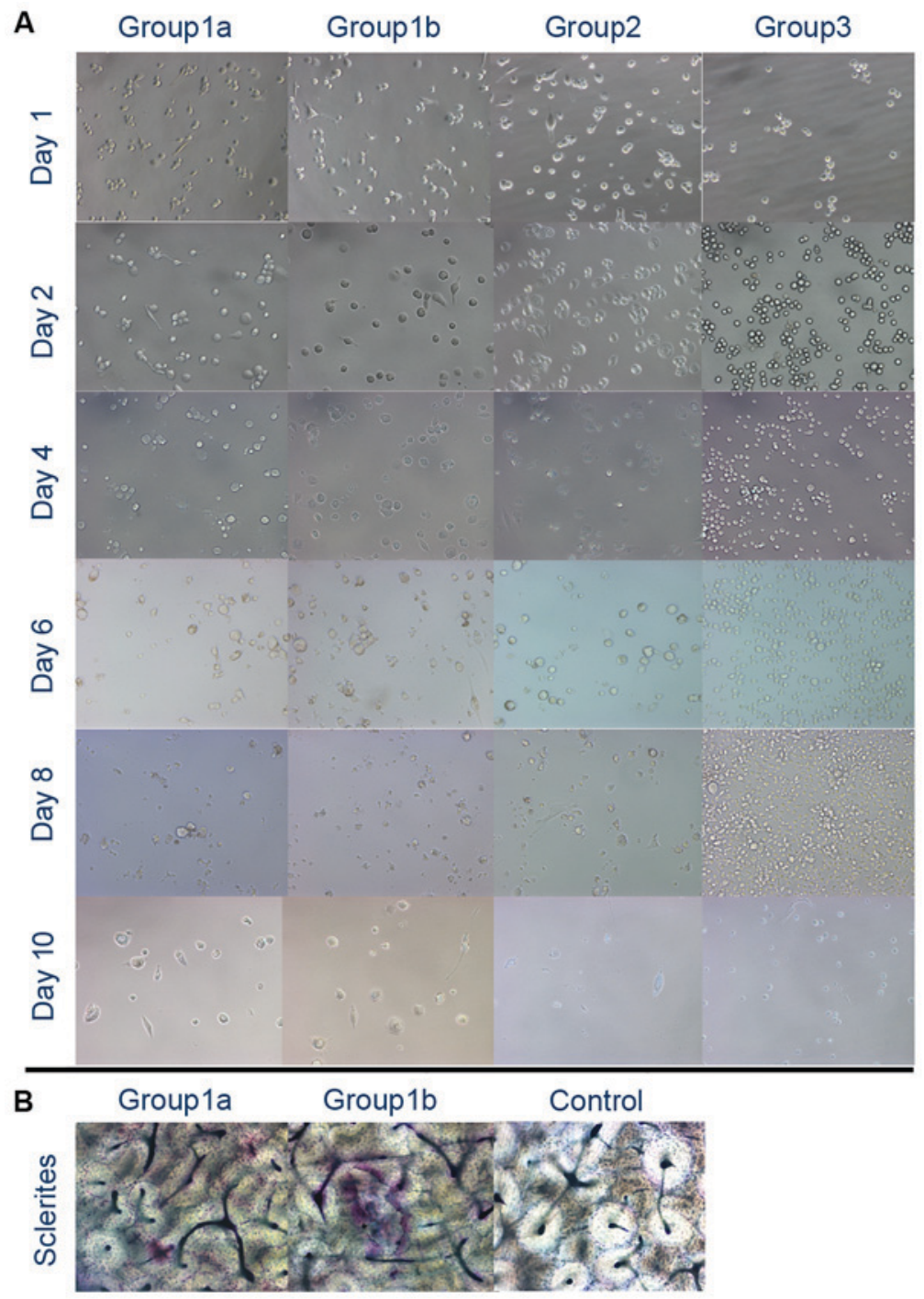

Figure 2. Two-step stimulation using PMA with RANKL and MCSF. (A) Cellular morphology (magnification, x200): In group 1a and group $1 \mathrm{~b}$, following $48 \mathrm{~h}$ of stimulation with PMA, the cells became adherent. RANKL and MCSF promoted further fusion in group 1a and group 1b; however, little distinction was observed between the two groups. In group 2, the cells became adherent following $48 \mathrm{~h}$ of stimulation with PMA and the cells remained adherent, although with no apparent fusion, at the end of the observation. In group 3, following $48 \mathrm{~h}$ of stimulation with RANKL and MCSF, no clear alteration was observed. (B) At day 12, bone lacunae were observed solely in group $1 \mathrm{~b}$ (magnification, x200). PMA, phorbol-12 myristate-13 acetate; RANKL, receptor activator of nuclear factor k-B ligand; MCSF, macrophage colony stimulating factor.

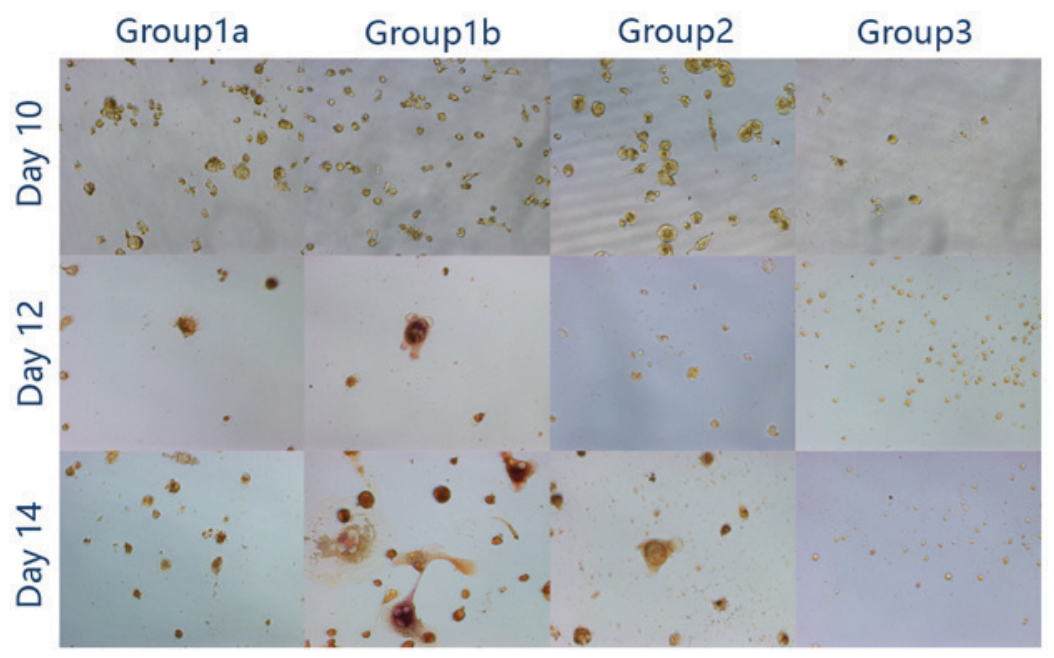

Figure 3. TRAP staining. At day 10, no TRAP-positive cells were identified across all the groups. At day 12, TRAP-positive cells were observed in group 1b. TRAP-positive cells were characterized by wine-red particles in the cytoplasm and $>2$ nuclei. At day 14, TRAP-positive cells were evident in group $1 \mathrm{~b}$; however, they were not present in the other groups (magnification, x400). TRAP, tartrate-resistant acid phosphatase. 
At present, the cell types which have been used in osteoclast models are murine BMCs, murine RAW 264.7 cells and human PBMCs. BMCs from mice may imitate the formation of true osteoclasts; however, it is difficult to obtain BMCs from humans. In order to investigate osteoclasts in humans, using PMBCs is a feasible method; however, there are ethical considerations and it is difficult to separate and purify monocytes from peripheral blood; using the classical method (10) typically yields few PMBCs, which additionally lack proliferation ability and exhibit a limited lifespan. In order to construct an osteoclast model, the THP-1 cell line was used. THP-1 cells are characterized by a high rate of proliferation and immortality. A large number of cells may be obtained within a short time and ethical issues, as well as the consideration of individual differences within human PMBCs, may be avoided.

In the present study, high-dose PMA combined with MCSF and RANKL was used to reliably induce osteoclast formation. The two-step method described in the present study mimics the two stages of osteoclast formation and provides a tool to investigate the mechanisms underlying the functions of osteoclasts. The method described in the present study is associated with the PKC and RANKL-RANK signaling pathways, which serve a role in bone resorption during inflammation. In order to construct an improved osteoclast model, it is suggested that the number of cells seeded be increased and that the culture time be prolonged.

\section{Acknowledgements}

The present study was supported in part by the National Natural Science Foundation of China (grant no. 81371082).

\section{References}

1. Soares-Schanoski A, Gómez-Piña V, del Fresno C, RodríguezRojas A, García F, Glaría A, Sánchez M, Vallejo-Cremades MT, Baos R, Fuentes-Prior P, et al: 6-Methylprednisolone downregulates IRAK-M in human and murine osteoclasts and boosts bone-resorbing activity: A putative mechanism for corticoid-induced osteoporosis. J Leukoc Biol 82: 700-709, 2007.

2. Charles JF and Aliprantis AO: Osteoclasts: More than 'bone eaters'. Trends Mol Med 20: 449-459, 2014.

3. Sloan AJ, Taylor SY, Smith EL, Roberts JL, Chen L, Wei XQ and Waddington RJ: A novel ex vivo culture model for inflammatory bone destruction. J Dent Res 92: 728-734, 2013.
4. Flecher X, Rolland C, Rixrath E, Argenson JN, Robert P, Bongrand $\mathrm{P}$, Wendling $\mathrm{S}$ and Vitte J: Local and systemic activation of the mononuclear phagocyte system in aseptic loosening of total hip arthroplasty. J Clin Immunol 29: 681-690, 2009.

5. Crump TB, Wimmer KL, Reinhardt AL, Schmid MJ, Meyer CR, Robinson DH, Marx DB, Bhattacharyya I and Reinhardt RA: Effects of locally-delivered human macrophage products and estrogen on murine inflammatory bone resorption. J Periodontal Res 37: 101-109, 2002.

6. Lee HP, Lin YY, Duh CY, Huang SY, Wang HM, Wu SF, Lin SC, Jean YH and Wen ZH: Lemnalol attenuates mast cell activation and osteoclast activity in a gouty arthritis model. J Pharm Pharmacol 67: 274-285, 2015

7. Kawamura H, Arai M and Togari A: Inhibitory effect of chlorpromazine on RANKL-induced osteoclastogenesis in mouse bone marrow cells. J Pharmacol Sci 117: 54-62, 2011.

8. Ueki Y, Lin CY, Senoo M, Ebihara T, Agata N, Onji M, Saheki Y, Kawai T, Mukherjee PM, Reichenberger E and Olsen BR: Increased myeloid cell responses to M-CSF and RANKL cause bone loss and inflammation in SH3BP2 'cherubism' mice. Cell 128: 71-83, 2007.

9. Jung YK, Han SW, Kim GW, Jeong JH, Kim HJ and Choi JY: DICAM inhibits osteoclast differentiation through attenuation of the integrin $\alpha \mathrm{V} \beta 3$ pathway. J Bone Miner Res 27: 2024-2034, 2012.

10. Petrova NL, Petrov PK, Edmonds ME and Shanahan CM: Novel use of a Dektak 150 surface profiler unmasks differences in resorption pit profiles between control and Charcot patient osteoclasts. Calcif Tissue Int 94: 403-411, 2014.

11. Uchiyama S and Yamaguchi M: Inhibitory effect of beta-cryptoxanthin on osteoclast-like cell formation in mouse marrow cultures. Biochem Pharmacol 67: 1297-1305, 2004.

12. Park EK, Jung HS, Yang HI, Yoo MC, Kim C and Kim KS: Optimized THP-1 differentiation is required for the detection of responses to weak stimuli. Inflamm Res 56: 45-50, 2007.

13. Tundup S, Srivastava L, Nagy T and Harn D: CD14 influences host immune responses and alternative activation of macrophages during Schistosoma mansoni infection. Infect Immun 82: 3240-3251, 2014.

14. Yang RF, Zhao GW, Liang ST, Chen HZ and Liu DP: Lysinespecific demethylase 1 represses THP-1 monocyte-to-macrophage differentiation. Chin Med Sci J 28: 82-87, 2013.

15. Pivetta E, Wassermann B, Bulian P, Steffan A, Colombatti A, Polesel J and Spessotto P: Functional osteoclastogenesis: The baseline variability in blood donor precursors is not associated with age and gender. Oncotarget 6: 31889-31900, 2015.

16. Ritchlin CT, Haas-Smith SA, Li P, Hicks DG and Schwarz EM: Mechanisms of TNF-alpha- and RANKL-mediated osteoclastogenesis and bone resorption in psoriatic arthritis. J Clin Invest 111: 821-831, 2003.

17. Wang Y, Dong G, Jeon HH, Elazizi M, La LB, Hameedaldeen A, Xiao E, Tian C, Alsadun S, Choi Y and Graves DT: FOXO1 mediates RANKL-induced osteoclast formation and activity. J Immunol 194: 2878-2887, 2015. 